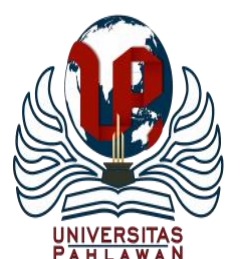

Jurnal Abdidas Volume 2 Nomor 5 Tahun 2021 Halaman 1029-1036

JURNAL ABDIDAS

http://abdidas.org/index.php/abdidas

\title{
Penyuluhan Pelaksanaan Ketahanan Ekonomi melalui Program Kewirausahaan dengan Menggunakan Digital Marketing di Era Pandemi
}

\author{
Novita Wahyu Setyawati ${ }^{1 凶}$, Dewi Sri Woelandari PG $^{2}$, Agus Dharmanto ${ }^{3}$, Eri Bukhari ${ }^{4}$ \\ Manajemen, Universitas Bhayangkara Jakarta Raya Bekasi, Indonesia ${ }^{1,2,3,4}$ \\ E-mail : Novita.wahyu@dsn.ubharajaya.ac.id ${ }^{1}$ dewi.sri@dsn.ubharajaya.ac.id ${ }^{2}$ \\ agus.dharmanto@dsn.ubharajaya.ac.id ${ }^{3} \underline{\text { eri bukhari@yahoo.com }}^{4}$
}

\begin{abstract}
Abstrak
Kegiatan pengabdian kepada masyarakat yang akan dilaksanakan berupa penyuluhan kepada masyarakat melalui kegiatan pendampingan akan ketahanan ekonomi di situasi pandemik Covid-19. Dalam kegiatan ini, metode yang digunakan adalah metode pengumpulan data, menentukan tema pengabdian yang akan diberikan, mencari studi pustaka, membuat materi kegiatan, menyajikan penyuluhan dan pelatihan (praktik) dan melakukan kegiatan monitoring dan evaluasi. Hasil dari kegiatan ini, warga dapat menghasilkan produk dari hasil praktik dan produk tersebut bisa menjadikan peluang produk wirausaha di situasi pandemi saat ini. Serta dapat menjadikan income untuk masyarakat sekitar. Dalam memasarkan produk tersebut, cukup melalui digital marketing. Pelaksanaan kegiatan pengabdian kepada masyarakat di lingkungan RT. 005/ RW. 001, Kel. Marga Mulya, Kec. Bekasi Utara Kota Bekasi berjalan dengan baik dan lancar. Partisipasi dan dukungan masyarakat cukup tinggi, di mana masyarakat mau membantu melaksanakan program sehingga masyarakat dapat mengambil manfaatnya.
\end{abstract}

Kata kunci: pengabdian kepada masyarakat, ketahanan ekonomi, program kewirausahaan, Covid-19

\section{Abstract}

Community service activities that will be carried out are in the form of counseling the community through mentoring activities on economic resilience in the Covid-19 pandemic situation. In this activity, the methods used are data collection methods, determining the theme of service to be given, looking for literature studies, making activity materials, presenting counseling and training (practice) and carrying out monitoring and evaluation activities. The results of this activity, residents can produce products from the results of the practice and these products can make entrepreneurial product opportunities in the current pandemic situation and can make income for the surrounding community. In marketing these products, it is enough through digital marketing. Implementation of community service activities in the RT. 005/RW. 001 Kel. Marga Mulya, Kec. North Bekasi Bekasi City is running well and smoothly. Community participation and support is quite high, where the community is willing to help implement the program so that the community can benefit from it. Keywords: community service, economic resilience, entrepreneurship program, Covid-19

Copyright (c) 2021 Novita Wahyu Setyawati, Dewi Sri Woelandari PG, Agus Dharmanto, Eri Bukhari $\checkmark$ Corresponding author

Address : Universitas Bhayangkara Jakarta Raya Bekasi

Email : Novita.wahyu@dsn.ubharajaya.ac.id

ISSN 2721- 9224 (Media Cetak)

DOI : https://doi.org/10.31004/abdidas.v2i5.409

ISSN 2721- 9216 (Media Online) 
1030 Penyuluhan Pelaksanaan Ketahanan Ekonomi melalui Program Kewirausahaan dengan Menggunakan Digital Marketing di Era Pandemi- Novita Wahyu Setyawati, Dewi Sri Woelandari PG, Agus Dharmanto, Eri Bukhari

DOI: https://doi.org/10.31004/abdidas.v2i5.409

\section{PENDAHULUAN}

Sehubungan dengan kondisi pandemi Covid-19, adanya kegiatan pengabdian kepada masyarakat merupakan suatu bentuk pendidikan antara dosen dan mahasiswa-mahasiswi yang dapat membantu memberikan edukasi sekaligus melatih dalam meningkatkan kapasitas diri dengan cara terlibat langsung dan berperan serta dalam melakukan upaya membantu masyarakat di daerah lokasi pengabdian untuk pencegahan, pemutusan rantai penyebaran Covid-19, meningkatkan ketahanan ekonomi masyarakat untuk siaga, sigap sehingga menjadi desa tangguh menghadapi bencana wabah Covid-19.

Karyawan perusahaan atau pabrik-pabrik mengalami PHK dan dirumahkan sampai dengan waktu yang belum pasti kapan berakhir. Tentunya, banyak dari mereka yang masih menunggu kepastian mengenai tetap bisa bekerja seperti sedia kala atau pasrah dengan kondisi yang terjadi saat ini, namun kebutuhan hidup keluarga tetap harus berjalan.

Pembatasan Sosial Berskala Besar (PSBB) yang berlaku mengharuskan aktivitas warga dilakukan dari rumah atau secara daring. Hal ini tentunya membuat tingkat daya beli masyarakat menurun drastis karena mayoritas kegiatan pemenuhan kebutuhan hidup dilakukan secara konvensional, terutama bagi keluarga miskin dan rentan yang bekerja di sektor informal. Akan tetapi, jika pada saatnya PSBB dilonggarkan oleh pemerintah hal ini dapat dilihat sebagai suatu peluang bagi masyarakat, khususnya anak muda untuk berwirausaha.
Salah satu cara yang dirasa cukup ampuh adalah menumbuhkan dan menguatkan jiwa wirausaha (entrepreneurship), terutama di kalangan milineal. Diharapkan dengan menguatnya pemikiran serta tindakan kewirausahaan yang semakin masif, masyarakat dapat hidup mandiri dan bertahan sekalipun di tengah situasi sulit seperti saat ini. Entrepreneurship memiliki dampak positif bagi suatu perekonomian dan masyarakat. Salah satu dampak terpenting dari entrepreneurship adalah penyediaan lapangan pekerjaan. Inovasi merupakan alasan kedua yang memberikan dampak positif bagi kekuatan ekonomi dan masyarakat di tengah wacana "era norma baru". Inovasi berkaitan dengan proses menciptakan sesuatu yang baru dan membantu individu untuk bekerja secara lebih efektif dan efisien. Perilaku kewirausahaan juga menjadi faktor penting dalam menjalankan bisnis, di mana adanya pengaruh yang signifikan antara pengetahuan berwirausaha, motif berprestasi, kemandirian berusaha terhadap perilaku berwirausaha (Elistia, 2020).

Melalui inovasi munculah kebaharuan yang dapat berbentuk produk baru hingga sistem distribusi baru. Produk baru misalnya, tidak mesti terkait dengan teknologi canggih karena produk yang sederhana juga dapat menyajikan kebaharuan

Produk baru yang dihasilkan dalam memasarkan produknya, tidak dapat dilakukan secara metode manual. Sehingga perlu adanya sosialisasi tentang pentingnya bisnis berbasis digital marketing. Karena dengan memanfaatkan 
1031 Penyuluhan Pelaksanaan Ketahanan Ekonomi melalui Program Kewirausahaan dengan Menggunakan Digital Marketing di Era Pandemi- Novita Wahyu Setyawati, Dewi Sri Woelandari PG, Agus Dharmanto, Eri Bukhari

DOI: https://doi.org/10.31004/abdidas.v2i5.409

digital marketing dapat memperluas jangkauan pasar. Dengan melakukan promosi dan penjualan produk dengan internet, setiap orang dapat melihat produk yang dimiliki sehingga mempermudah pengenalan produk kepada calon konsumen. Pemesanan lewat online memudahkan konsumen untuk mencari informasi tentang produk yang dimiliki. Pemanfaatan penjualan online juga memberikan manfaat lainnya yaitu dapat meningkatkan efisiensi bisnis, karena bisnis tidak lagi terbatas oleh ruang dan waktu, terlebih lagi di situasi sekarang ini. Salah satu faktor yang menyebabkan pendistribusian barang kurang meluas karena belum melakukan pemasaran online. Hal ini dikarenakan dalam praktiknya masih kurang maksimal, sehingga hasil yang didapat pun kurang maksimal. Kurangnya pengetahuan sampai dengan adaptasi terhadap internet dan perkembangan teknologi menjadi tantangan dan masalah yang harus dihadapi (Susanti et al., 2020).

Lokasi kegiatan saat ini, kami lakukan di RT.005/RW.001, Kel. Marga Mulya, Kec. Bekasi Utara, Kota Bekasi. Pada lokasi tersebut, warganya sangat kreatif dalam melihat peluang yang ada apalagi dengan adanya kondisi saat ini. Mereka cenderung ingin mencari kegiatan yang bermanfaat dan setidaknya bisa menjadi sumber pendapatan bagi mereka. Maka dari itu, kami dari tim pelaksana pengabdian, ingin melakukan kegiatan untuk bisa mempertahankan ekonomi mereka dengan melihat peluang yang ada.

Kelurahan Marga Mulya berada di wilayah Kecamatan Bekasi Utara Kota Bekasi Provinsi
Jawa Barat. Kelurahan ini memiliki luas wilayah menurut penggunaan 259,09 $\mathrm{Ha}$, tanah sawah 9,00Ha, dan tanah kering 220,83 Ha. Dengan batas wilayah:

- Sebelah Utara : Kel. Harapan Baru dan Kel. Perwira

- Sebelah Selatan: Kel. Marga Jaya

- Sebelah Timur : Kel. Bekasi Jaya

- Sebelah Barat : Kel. Harapan Jaya dan Kel. Harapan Mulya

Dilihat dari segi kontur tanah yang ada di wilayah ini merupakan dataran rendah.

Berdasarkan keadaan umum dan hasil survei dalam kondisi saat ini, maka tim kami akan mengusung program atau kegiatan mengenai Penyuluhan Pelaksanaan Ketahanan Ekonomi melalui Program Kewirausahaan dengan Menggunakan Digital Marketing di Era Pandemi.

\section{METODE}

Metode kegiatan yang dilakukan oleh dosen dan mahasiswa-mahasiswi yang terdiri dari Program Studi Manajemen. Untuk menunjang kegiatan ini, maka rincian metode pelaksanaan yang akan dilakukan yaitu:

\section{Metode Pengumpulan Data}

Digunakan untuk mengumpulkan data-data mengenai kegiatan yang telah dilakukan oleh pihak RT. 005/ RW. 001 Kel. Marga Mulya, Kec. Bekasi Utara dalam ketahanan ekonomi. 
1032 Penyuluhan Pelaksanaan Ketahanan Ekonomi melalui Program Kewirausahaan dengan Menggunakan Digital Marketing di Era Pandemi- Novita Wahyu Setyawati, Dewi Sri Woelandari PG, Agus Dharmanto, Eri Bukhari

DOI: https://doi.org/10.31004/abdidas.v2i5.409

\section{Menentukan Tema Pengabdian yang} Akan Diberikan

Berdasarkan survei telah dilakukan dan diuraikan secara rinci pada latar belakang, sehingga tema pengabdian kepada masyarakat yaitu Penyuluhan Pelaksanaan Ketahanan Ekonomi melalui Program Kewirausahaan dengan Menggunakan Digital Marketing di Era Pandemi.

\section{Mencari Studi Pustaka}

Studi pustaka adalah teknik pengumpulan data referensi dari berbagai jenis sumber keilmuan yang menunjang dalam menemukan solusi permasalahan, serta berbagai teori dan implementasi tentang tema ini.

\section{Membuat Materi Kegiatan}

Berdasarkan studi pustaka yang telah dilakukan maka dibuatlah materi kegiatan, berupa penyuluhan dan pelatihan (praktik). Praktik yang dilakukan adalah membuat langsung desinfektan, hand sanitizer dan masker.

\section{Menyajikan Penyuluhan dan Pelatihan (Praktik).}

Penyuluhan dan pelatihan (praktik) dengan materi yang berkaitan dengan program/kegiatan yang telah ditentukan. Di mana bahan-bahan untuk praktik disediakan oleh tim pelaksana kegiatan seperti: bahanbahan untuk desinfektan, hand sanitizer, dan masker. Selain itu, tim juga memberikan penyuluhan mengenai pemasaran produk usahanya nanti dengan selain mouth to mouth juga menggunakan sistem digital, sehingga jangkauan pemasarannya lebih luas.

\section{Melakukan Kegiatan Monitoring Dan} Evaluasi

Monitoring dan evaluasi dilakukan untuk melihat sejauh mana perkembangan hasil dari pelaksanaan pengabdian kepada masyarakat. Kegiatan ini akan tetap di monitoring oleh tim walaupun waktu pelaksanaan telah berakhir. Agar materi yang sudah diajarkan dapat diteruskan sendiri oleh warga setempat. Walaupun kegiatan telah berakhir, akan tetapi kami sebagai pelaksana kegiatan tetap melakukan pendampingan pada warga guna melihat perkembangan selanjutnya. Apakah yang telah diajarkan berjalan terus atau tidak atau produk yang dihasilkan sudah semakin baik atau belum.

\section{HASIL DAN PEMBAHASAN}

Kegiatan pengabdian kepada masyarakat di lingkungan RT. 005/ RW. 001 Kel. Marga Mulya, Kec. Bekasi Utara Kota Bekasi dilakukan pada hari/tanggal Jumat-Sabtu, 18-19 Juni 2021. Beberapa program kerja yang dilakukan di antaranya cara pembuatan cairan desinfektan, pembuatan cairan hand sanitizer, dan pembuatan masker. Beberapa permasalahan yang sudah dijelaskan pada bab 1 pendahuluan, di mana didukung dengan gambaran umum dan dijabarkan pada bab selanjutnya, membuat tim Pengabdian kepada Masyarakat (PKM) merumuskan beberapa 
1033 Penyuluhan Pelaksanaan Ketahanan Ekonomi melalui Program Kewirausahaan dengan Menggunakan Digital Marketing di Era Pandemi- Novita Wahyu Setyawati, Dewi Sri Woelandari PG, Agus Dharmanto, Eri Bukhari

DOI: https://doi.org/10.31004/abdidas.v2i5.409

fokus permasalahan yang akan diselesaikan.

Proses pemilihan prioritas permasalahan ini tentunya berangkat dari hasil wawancara secara mendalam bersama dengan mitra dan analisis terkait kemungkinan yang ada dan bisa dilaksanakan secara maksimal sesuai kebutuhan mitra. Berikut ini adalah serangkaian hasil dari kegiatan yang dilakukan oleh tim beserta masyarakat adalah sebagai berikut:

1. Kegiatan Pembuatan Desinfektan

\section{Alat yang diperlukan:}

- Botol semprot plastik.

- Botol kaca dengan tutup.

- Gelas ukur.

- Lap flanel atau kain microfiber atau kain lembap.

- Sarung tangan sekali pakai.

- Masker N95 atau masker bedah.

\section{Bahan yang dibutuhkan:}

- 2 sendok makan (30 ml) cairan pemutih pakaian, untuk 1 liter air.

- Air bersih.

\section{Yang harus diperhatikan:}

Contoh perhitungan dalam artikel ini adalah menggunakan cairan pemutih pakaian dengan kadar 5\% untuk kemudian diencerkan hingga kadarnya mencapai $0.05 \%$. Untuk mencapai kadar $0.05 \%$ sebagai produk akhir, maka dilakukan perbandingan 1:100. Misalnya, 1 bagian bahan pemutih untuk 99 bagian air. Di pasaran, cairan pemutih pakaian tersedia dengan kadar dari 2,5-5\%. Jadi, pastikan untuk selalu menghitung perbandingannya dengan benar agar konsentrasi produk akhir tetap mencapai $0.05 \%$ agar didapat perbandingan 1:100.

\section{Cara membuat dan menggunakannya:}

- Tuang cairan pemutih pakaian secara hati-hati ke dalam botol kaca terlebih dahulu. Lalu, tambahkan air bersih dan aduk hingga tercampur dengan merata.

- Jika sudah, tutup botol kaca dengan rapat, lalu kocok secara perlahan agar cairan pemutih pakaian dapat tercampur sempurna dengan air.

- Apabila larutan cairan pemutih pakaian sudah tercampur sempurna, Anda bisa membagikan larutan cairan pemutih pakaian tersebut ke dalam botol semprot yang lebih kecil agar mudah digunakan.

- Cairan desinfektan sudah siap digunakan. Anda dapat membersihkan permukaan benda mati yang sering disentuh dengan sabun dan air panas bersih terlebih dahulu sebelum menggunakan cairan desinfektan.

Hasil yang didapat dari pembuatan desinfektan, sudah cukup baik dan para peserta sangat antusias dan aktif dalam kegiatan ini, dan ada yang ingin terus belajar membuatnya sampai berhasil dengan baik.

2. Kegiatan Pembuatan Cairan Hand Sanitizer

\section{Bahan yang diperlukan:}

- 3/4 cangkir isopropil atau alkohol (99 persen). 
1034 Penyuluhan Pelaksanaan Ketahanan Ekonomi melalui Program Kewirausahaan dengan Menggunakan Digital Marketing di Era Pandemi- Novita Wahyu Setyawati, Dewi Sri Woelandari PG, Agus Dharmanto, Eri Bukhari

DOI: https://doi.org/10.31004/abdidas.v2i5.409

- 1/4 cangkir gel lidah buaya (untuk membantu menjaga tangan tetap halus dan untuk menangkal kerasnya alkohol).

- 10 tetes minyak esensial, seperti minyak lavender, atau bisa menggunakan jus lemon.

Hasil yang didapat dari pembuatan cairan hand sanitizer, sudah cukup baik dan para peserta sangat antusias dan aktif dalam kegiatan ini, dan ada yang ingin terus belajar membuatnya sampai berhasil dengan baik.

3. Kegiatan Pembuatan Masker dari Bahan Kain.

Hasil yang didapatkan masker dari bahan kain masih belum sempurna. Penjahitan pada masker masih kasar, tidak rapih dan warna bahan kainnya kurang lembut, sehingga banyak yang masih harus diperbaiki. Masker yang dibuat juga masih banyak yang hasilnya kurang rapih, masih terlihat benang-benang yang menonjol dan kasar. Meskipun hasilnya masih kurang memuaskan, tetapi para peserta sangat antusias dan aktif dalam kegiatan ini, dan ada yang ingin terus belajar membuatnya sampai berhasil dengan baik.

Dari hasil keseluruhan kegiatan yang telah dilakukan tim dengan masyarakat, maka hasil yang telah dihasilkan, seperti masker, hand sanitizer dan desinfektan walaupun belum terlalu sempurna. Akan tetapi bisa menjadikan peluang produk wirausaha di situasi pandemi saat ini. Serta dapat menjadikan income untuk masyarakat sekitar. Dalam memasarkan produk tersebut cukup melalui digital marketing. Dampak serta manfaat yang didapat dari masyarakat sangat baik, di mana dampak dari program kegiatan ini dapat menciptakan peluang usaha baru bagi masyarakat dikarenakan pada situasi pandemik banyak perusahaan yang merumahkan karyawannya. Sedangkan manfaat yang didapat dari program kegiatan ini adalah dapat menciptakan kemandirian masyarakat dalam mempertahankan ekonomi keluarganya, walaupun tidak terlalu berharap menghasilkan dalam jumlah rupiah yang besar akan tetapi bisa bertahan dalam kondisi saat ini.

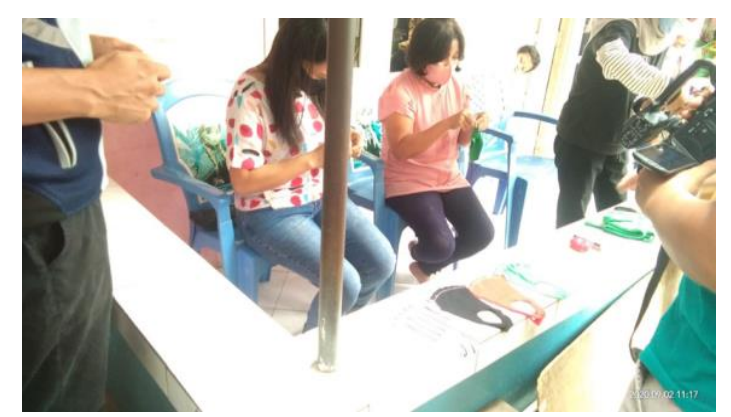

Gambar 1. Praktik Pembuatan Masker dan Hand Sanitizer

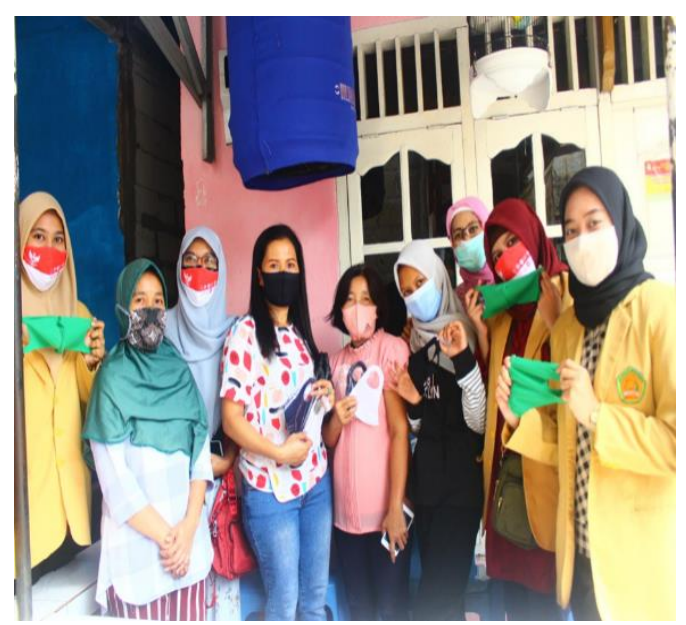

Gambar 2. Hasil Produk Warga 
1035 Penyuluhan Pelaksanaan Ketahanan Ekonomi melalui Program Kewirausahaan dengan Menggunakan Digital Marketing di Era Pandemi- Novita Wahyu Setyawati, Dewi Sri Woelandari PG, Agus Dharmanto, Eri Bukhari

DOI: https://doi.org/10.31004/abdidas.v2i5.409

\section{SIMPULAN}

Pelaksanaan kegiatan pengabdian kepada masyarakat di lingkungan RT. 005/ RW. 001 Kel. Marga Mulya, Kec. Bekasi Utara Kota Bekasi berjalan dengan baik dan lancar. Program yang dilaksanakan yaitu:

1. Pembuatan desinfektan

2. Pembuatan cairan hand sanitizer

3. Pembuatan masker

Adanya partisipasi dan dukungan masyarakat yang cukup tinggi, program kegiatan ini dapat menghasilkan produk-produk yang telah dilaksanakan seperti: masker, desinfektan, dan hand sanitizer. Walaupun produk yang dihasilkan masih sangat sederhana, akan tetapi dapat diperbaiki untuk kedepannya. Sehingga dengan adanya produk-produk yang ada dapat menciptakan peluang bagi masyarakatnya dalam berwirausaha di situasi pandemik, dengan memasarkan secara digital marketing.

Berdasarkan kegiatan yang telah dilaksanakan oleh para dosen dan mahasiswa Universitas Bhayangkara Jakarta Raya yang dilaksanakan di lingkungan RT. 005/ RW. 001 Kel. Marga Mulya, Kec. Bekasi Utara Kota Bekasi. Dengan tujuan untuk memberikan masukan kepada berbagai pihak yang terkait dalam pelaksanaan kegiatan ini yang diharapkan dapat berguna untuk peningkatkan mutu dan kualitas semua pihak, antara lain sebagai berikut:

1. Bagi dosen dan mahasiswa

a. Meningkatkan kekerabatan dan sosialisasi kepada masyarakat desa. b. Dalam penyusunan program hendaknya disesuaikan dengan situasi dan kondisi lokasi kegiatan, pertimbangan dana, tenaga dan waktu yang tersedia.

c. Lebih meningkatkan disiplin diri dalam kegiatan pengabdian kepada masyarakat.

d. Menjalin kerjasama yang baik antar dosen dan mahasiswa.

2. Bagi Masyarakat

Masyarakat hendaknya mengerti bahwa kegiatan ini bukan hanya untuk kepentingan dosen dan mahasiswa saja tetapi kepentingan masyarakat lingkungan setempat, di mana dosen dan mahasiswa hanya sebagai narasumber dan motivasi yang membantu mencegah masalah sehingga diharapkan partisipasi masyarakat dalam setiap program kegiatan.

\section{UCAPAN TERIMA KASIH}

Terima kasih kami ucapkan kepada Lembaga Penelitian Pengabdian kepada Masyarakat Universitas Bhayangkara Jakarta Raya yang telah mendukung penuh untuk kelancaran pelaksanaan program pengabdian masyarakat, serta Ketua RT. 005/ RW. 001 Kel. Marga Mulya, Kec. Bekasi Utara Kota Bekasi dan seluruh warga, teman-teman dosen dan mahasiswa-mahasiswi yang telah membantu upaya pelaksanaan kegiatan mulai dari survei sampai pelaksanaan. 
1036 Penyuluhan Pelaksanaan Ketahanan Ekonomi melalui Program Kewirausahaan dengan Menggunakan Digital Marketing di Era Pandemi- Novita Wahyu Setyawati, Dewi Sri Woelandari PG, Agus Dharmanto, Eri Bukhari

DOI: https://doi.org/10.31004/abdidas.v2i5.409

\section{DAFTAR PUSTAKA}

A. Susanti, B. I. (2020). Strategi UKM pada Masa Pandemi Covid-19. Karya Ilmiah Pengabdian Masyarakat.

Elistia. (2020). Analysis of Entrepreneurial Knowledge, Achievement Motives And Business Independence towards Entrepreneurial Behavior In Joint Business Groups. . Journal of Research in Business, Economics and Education. 